\title{
The Integration of Graphic Disciplines in Civil Engineering Courses through Computer Graphics
}

\author{
Gisele L. de Carvalho ${ }^{1}$, Ana C. R. Cavalcanti ${ }^{1}$, Flávio A. M. de Souza ${ }^{1}$ and Letycia V. P. da Silva ${ }^{2}$ \\ 1. The Department of Graphic Expression, Federal University of Pernambuco, Recife 50740-530, Brazil \\ 2. The Department of Civil Engineer, Federal University of Pernambuco, Recife 50740-530, Brazil
}

\begin{abstract}
This paper presents the partial results of a project in progress that aims to improve the teaching and learning of Graphic Geometry modules taught in Engineering and Civil Engineering courses at the Federal University of Pernambuco through the development of education methodologies and content integration of these disciplines using computational technologies. This study covers and analyzes the contents of Tridimensional Graphic Geometry, Technical Drawing 3 and Descriptive Geometry in the BSc course in Civil Engineering, in order to create an integrated assessment model across these disciplines from the use of specific computer graphic softwares. It is proposed to use computer graphic for: (i) concept formation, (ii) completing and/or reviewing the content, (iii) creation of a database with virtual geometric models and their applications in Engineering and for the studies of their representations, geometric properties, etc., providing digital images of everyday forms and objects. In order to begin the diagnosis of the current situation, we gave an open questionnaire to 65 students from the 16 groups of three-dimensional graphical geometry, 20 students from the two courses in Technical Drawing 3 and 35 students from the three Descriptive Geometry classes. The analysis of the data suggests that students better understand the two-dimensional representations of three-dimensional models through their modeling with the computer graphics software used, and the association of abstract concepts with concrete content. From the analysis of the data we can verify that when our students enter the foundation Engineering courses, the main difficulty in the disciplines of drawing is the three-dimensional visualization. The hypothesis is that the student will better understand the two-dimensional representations of three-dimensional models through their modeling with the computer graphic software used and the association of abstract concepts with concrete content.
\end{abstract}

Key words: Teaching methodologies, integration of contents, computer technologies.

\section{Introduction}

The classical teaching resources of Graphic Geometry, such as set squares, giant rulers and compasses and educational books, are not always ideal for transmitting concepts and content to students, as some have difficulty in visualising two dimensional figures that, by their nature, have three dimensions. For this reason, a number of teachers use physical models to demonstrate characteristics that, on paper, would be difficult to learn.

In general, knowledge comes from a concrete problem, and is later systematized. But, in formal education, knowledge is presented, in most cases, in a

Corresponding author: Gisele Lopes de Carvalho, Ph.D., associate professor, research fields: descriptive geometry, technical drawing, CAD. general and abstract way, hindering its subsequent contextualization. With a view to meaningful learning, various educators have used modeling, to minimize the obstacles that hamper the formation of concepts by students.

Thus, by contextualizing problem situations and representing them graphically, many relationships and properties can be easily identified. However, a considerable knowledge of flat and spatial geometry is necessary for students to be able to represent three-dimensional geometric forms in two-dimensional space, where their study is usually developed (Fig. 1).

Concrete models or images in perspective have been used to facilitate learning by students, and through their construction, manipulation and visualization, better identification of their properties and training of the concepts. Silva and Lira [1], for example, presented the 

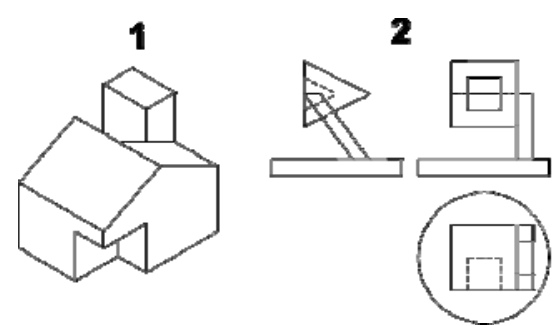

Fig. 1 Three-dimensional Graphic Geometry. Source: The authors.

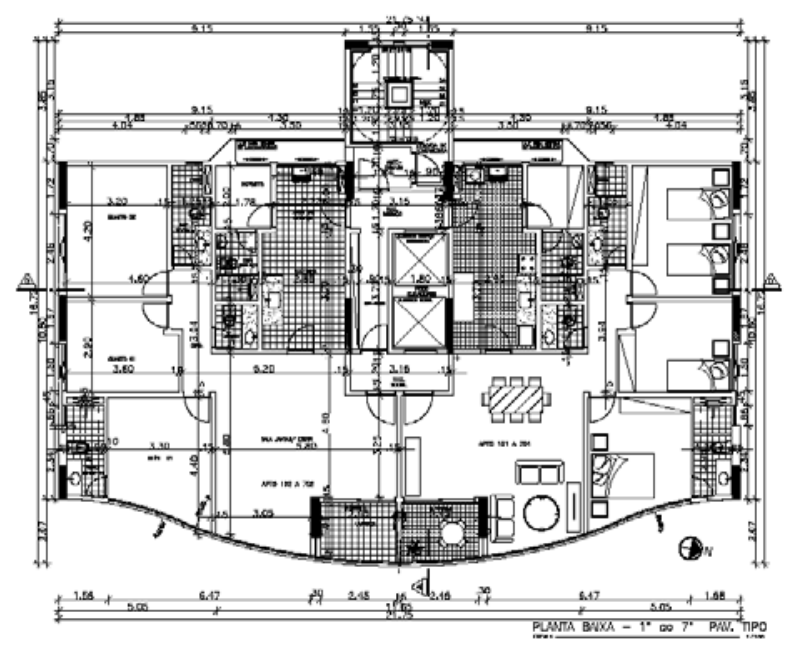

Fig. 2 Technical Drawing 3.

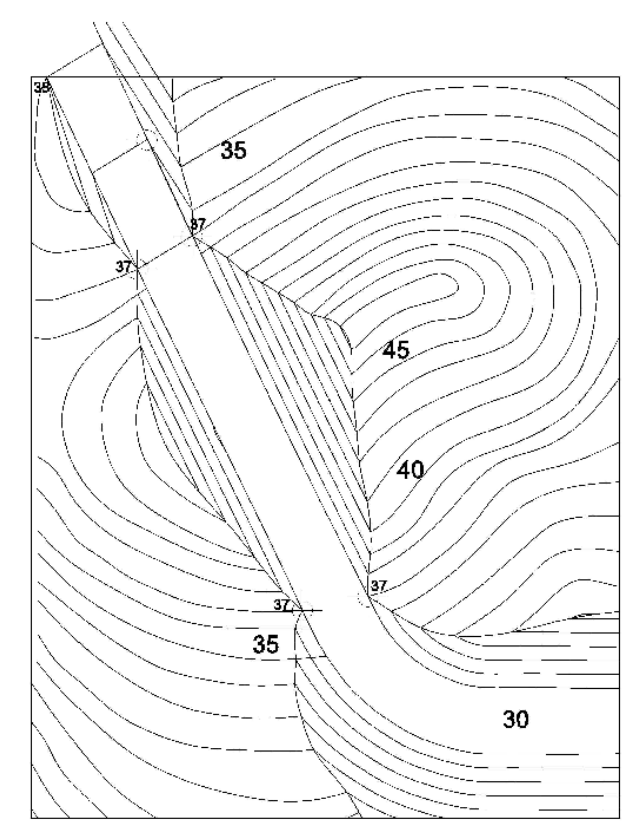

Fig. 3 Descriptive Geometry.

contents of Descriptive Geometry with animated images that, step by step, build the model of the Mongeano System. Vianello [2] proposes, for the teaching of Architectural Drawing (Fig. 2), that the student uses the experience of daily life, such as drawing the design of their own houses. Thus, working on something known makes it easier to understand its representation (Fig. 3). The paper is organized as follows: first we will present a theoretical foundation on the subject, then how was the methodological approach, in Section 3 the data analysis is presented and finally the results and conclusions.

\section{Theoretical Foundation}

Modern educational theories emphasize that in the cognitive development of the individual, the element that will imply the transformation and the consequent development of knowledge, is the way in which the individual elaborates information on the environment. Constructivist educational theories advocate the importance of the student manipulating the information presented, so he or she can construct their knowledge, since learning follows the way the individual transforms the information of the world in their mind.

Both constructivist and post-constructivist theories emphasize the importance of the subject's participation in the formation of knowledge. Vergnaud's theory of Conceptual Fields proposes that the obstacles presented by students can be detected not only from the conceptions of the subject, but also from their actions. It is necessary to identify situations that give meaning to a concept, the underlying operative invariants, as well as the various forms of symbolic representation of the problem or situation and their respective solutions.

The theory in focus assumes that much of our knowledge corresponds to competencies ${ }^{1}$, and that there are obstacles from these competencies that interfere with teaching and learning. Vernaud, based on Piaget (the action of the subject determines to the construction of the knowledge) proposes, as a way to

\footnotetext{
${ }^{1}$ Competence understood as the capacity that the subject has to face and solve a certain problem.
} 
access these "competences", to use the theory of representation, the theory of conceptualization and the theory of reference [3].

Focusing attention on the theory of representation, we see that the guarantee of the operability of a representation is its proximity to reality [3]. To represent is to show a situation through symbols, images or objects. The result of this representation by the subject will be in function of how he or she perceives the situation as (it is a type of mediation between the subject and the real).

The conceptualization will be in function of how the individual acts on reality. And the formation of the concept will depend on the reference that the subject has on the point in question, the meaning that it takes on as a function of the invariants and the signifier, which is the capacity for symbolic representation [4]. This implies that if a problem is only approached in one way, the subject will hardly be able to perceive it from other angles.

The reference is based on the schemas and their operative invariants that are triggered to arrive at the concept. In addition, the concept cannot be confused with a definition because the concept needs different situations and problems in order for it to acquire meaning. Thus, it is important that the teacher be aware of the underlying representations in order to plan the didactic strategies and understand the students' doubts and mistakes. In this way, every strategy must be mounted on top of the specificities of the contents.

Thus, in the study of Graphic Geometry, which concerns the two-dimensional representation of three-dimensional forms, where the relations between the real object and its flat representation present characteristics of transformations that break with the spatial dimension, it is necessary that the teacher develop strategies that facilitate the articulation and activation of student schemes.

\section{Methodology}

Taking as a premise that, for the formation of a concept, it is important to see a problem in various situations or facts, it can be inferred that - It is not sufficient for meaningful learning to exclusively use expository classes, which mostly contain monologues by the teacher. Due to the influences of their environment (television, internet, globalization, etc.), young people require a more dynamic relationship in the classroom so that it is involved in the teaching with learning making it essential to reformulate the methodologies at all levels of education.

Therefore, in order to bring to the classroom the available computational resources, as well as developing uses and/or to increasing them with new options, this project covers the contents of the disciplines of Three-Dimensional Graphic Geometry of Area II (Engineering courses), Technical Design 3 and Descriptive Geometry courses of the UFPE Civil Engineering course and studies with software aimed at: (i) concept formation, (ii) completing and/or reviewing the content, (iii) creation of a database with virtual geometric models and their applications in Engineering and the studies of their representations, properties, etc., providing digital images of everyday forms and objects.

In the discipline of Technical Drawing 3, whose content is Architectural Design, a methodology has been implemented that harmonizes freehand drawing and constructions by AutoCAD. Continuing the process of change and representation of forms with the computer, it is also intended to initiate the use of BIM (Building Information Modelling) softwares, as well as the use of these computational resources in the classes in which traditional drawing instruments are used to better present the elements involved in the design of an architectural project, such as stairs, flat roofs, metallic structures, shells, etc., and their consequent representation in the plan. In order to do this, examples will be introduced through digitalized images of constructed buildings, the final result and the way they are represented in a drawing.

In the discipline Three-Dimensional Graphic 
Geometry the use of software has not yet been implemented, although teachers use some digital tools in their theoretical classes; however, in Descriptive Geometry, software in the classroom was first used ten years ago, but only in one of the three courses, the other two continuing with paper and pencil. In this course, for the last three semesters a combined methodology has been developed working with pencil and paper and computer. In all disciplines, we have sought to present some of the contents covered through graphic animation, as well as the use of physical models which facilitate the visualization and comprehension of three-dimensionality by the students.

The hypothesis is that the student will better understand the two-dimensional representations of three-dimensional models through their modeling with the computer graphic software used and the association of abstract concepts with concrete content.

In order to begin the diagnosis of the current situation, we gave an open questionnaire to 65 students from the 16 groups of three-dimensional graphical geometry, 20 students from the two courses in Technical Drawing 3 and 35 students from the three Descriptive Geometry classes. These questionnaires were given in the first and second semester of 2015.

We will illustrate some of the graphs generated from the responses from these classes.

\section{Data Analysis}

As can be seen in Fig. 4, we could verify that when our students enter university, in the basic drawing disciplines of Engineering Courses (Three-Dimensional Graphic Geometry-TGG), the main difficulty mentioned is three-dimensional visualization.

In the following discipline (Descriptive Geometry) three-dimensional visualization is still the main difficulty followed by the adaptation to the instruments (Fig. 5).

Data indicate that the great majority of students (96\% of the total) considered the use of computational resources in regular classes of graphic geometry to be interesting, whilst only $4 \%$ stated that its use was unnecessary.

Qualitative data suggest that this difficulty is not mentioned again in Technical Drawing 3, not because it has been overcome, but because it is a discipline focused on two-dimensional architectural design, where three-dimensionality appears only in the physical and virtual models as a facilitator of the visualization of the project. In this, the difficulties mentioned were: lack of resources and lack of practice with the software (Fig. 6).

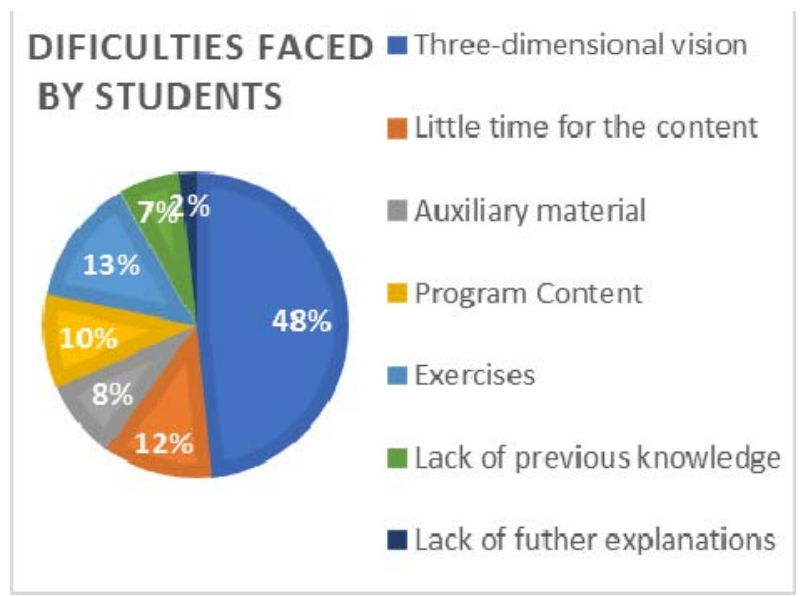

Fig. 4 Difficulties faced by students on learning graphic geometry in the first semester of their course (TGG).

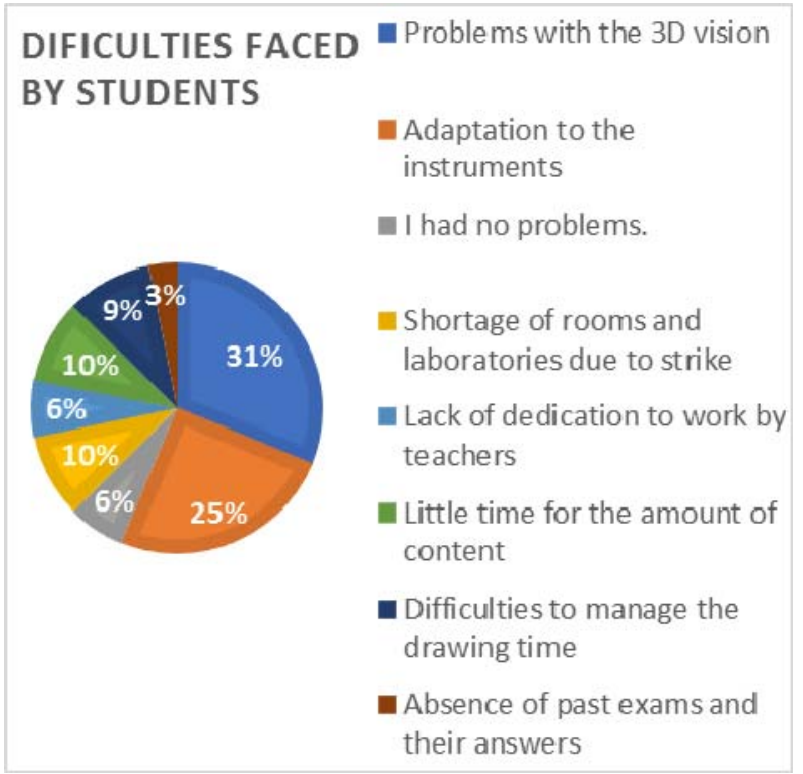

Fig. 5 Difficulties faced by students of Descriptive Geometry. 


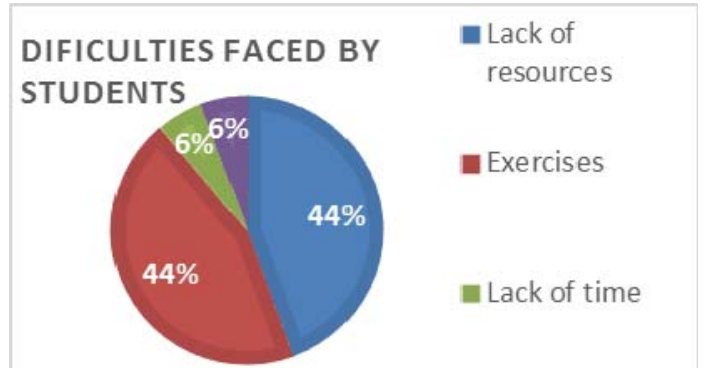

Fig. 6 Difficulties faced by students of Technical Drawing 3.

When we asked students about what could be improved, in Tridimensional Graphic Geometry after the improvement of the workbook, the use of computational resources to assist visualization appeared in second place. In the Descriptive Geometry classes the most cited questions were: laboratories with available AutoCAD, didactics and more exercises. In Technical Drawing 3 (already working in the computer lab) the most frequent problems were: improvement in materials, increase of the workload and more exercises.

The great majority (in all three disciplines) considered the use of computational resources positive in addition to regular classes (Figs. 7, 8 and 9).

As can be seen in Figs. 10 and 11, the great majority also considered that the integration of the content of the disciplines would be interesting.

In the question of what can be done to motivate the students, in the TGG classes the main answers were: the use of the computer lab and more practical examples (directed to Engineering). The Descriptive

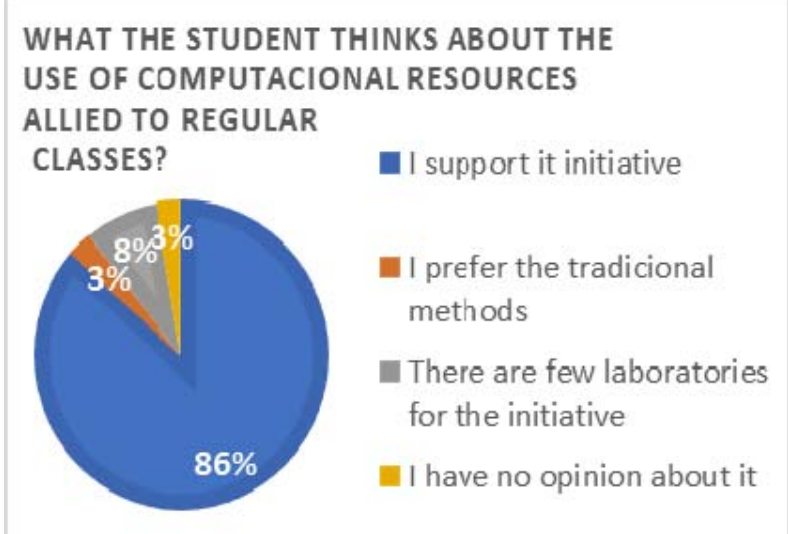

Fig. 7 Opinion of Descriptive Geometry students on the integration of computer and pencil.

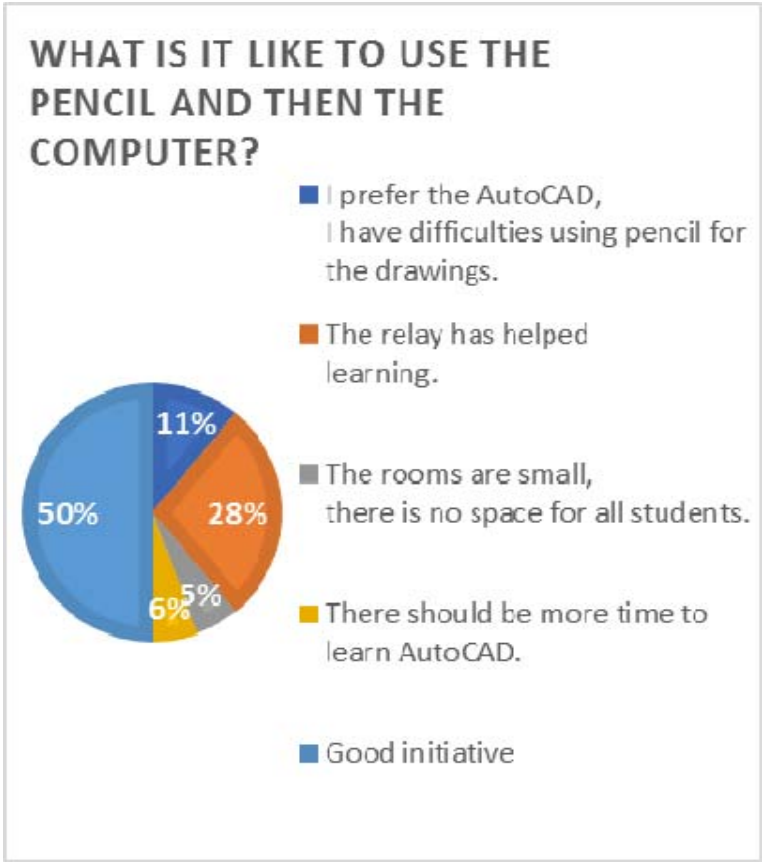

Fig. 8 Opinion of Technical Drawing 3 students on the use of pencil and then computer.

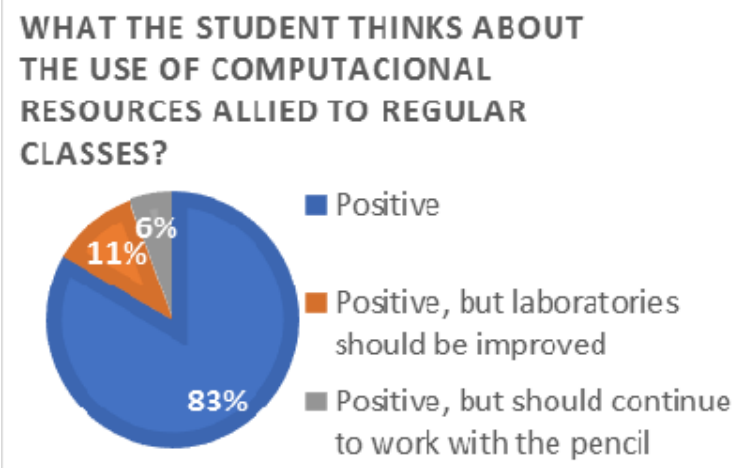

Fig. 9 Opinion of Technical Drawing 3 students on the integration of computer and pencil.

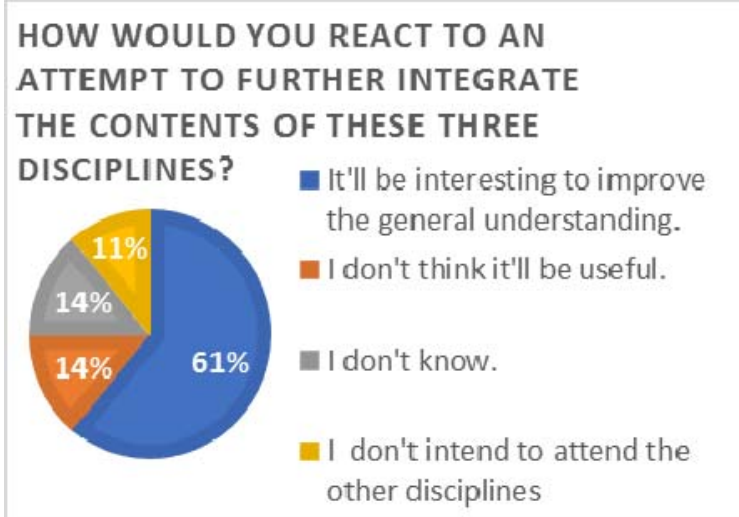

Fig. 10 Opinion of TGG students on the integration of the contents of the three disciplines. 


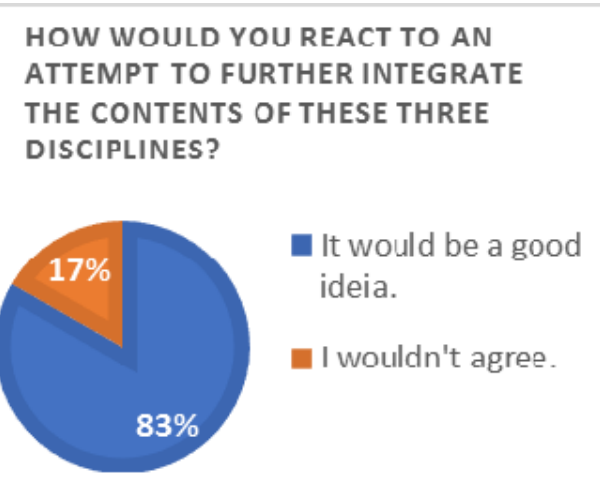

Fig. 11 Opinion of Descriptive Geometry students on the integration of the contents of the three disciplines.

Geometry classes responded in a similar way: using questions found in the student's professional lives and more AutoCAD. Students in Technical Drawing 3 (who have been working in AutoCAD) asked for more monitors and also examples of how to apply the knowledge acquired at the end of the course.

Considering this diagnosis and by observing the predisposition to change on the part of our students, we believe that a methodology integrating knowledge will solve the learning deficit of the three-dimensional visualization presented by the students. At the moment, after the data collection and the identification of the contents and their deficiencies, we are adapting the material studied to the digital medium and producing an integrated evaluation of the disciplines.

\section{Conclusions}

Monge's Descriptive Geometry is, still today, a basic discipline on the theoretical foundation of the act of designing, and is therefore of great importance in the areas of technology, exact sciences and arts. The methodology for its use needs to be revised, since computer graphics provide new resources and new means of representation.

Although the internal process by which machines construct drawings is by means of analytical geometry, and/or matrix and vector calculus, it is on the same Monge's Descriptive Geometry (the basis of the graphical representation on the drawing board) that computer graphics software is based to display graphic images on the computer screen. Therefore, though the working instrumental was changed, the guiding knowledge of spatial reasoning was still Descriptive Geometry.

However, in the computer workplace, the boundaries between the phases of a project seem to cease to exist. In fact, in terms of project representation, rather than distinct products, one always has the same product, represented at varying levels of detail and precision. A drawing can always be reused and added with new details, new information and possibly printed on a new scale [5].

This redefinition of work tools will require deeper formal and structural changes than the traditional measures of current pedagogical interventions. Although graphic computing exerts great influence and fascination on design professionals, its use does not eliminate the knowledge of representation systems. In general, simple or complex design problems will continue to exist for professionals working with graphic geometry (teachers, architects, engineers, designers, among others), since, in the scientific field of thought, the act of designing requires geometric reasoning [6].

The understanding of the new cognitive and communicative processes responsible for the conception, perception and apprehension of the built environment incorporated by the computer graphics in the Engineering courses is restricted by the permanence of teaching practices that still privilege cognitive and communicative models similar to those which use the traditional drawing tools. Most of the teachers who use graphic expression in engineering courses, do not understand the structures and tools of cognition and communication provided by computer graphics in the process of teaching and professional activity. This deficiency in the teaching/learning activity is not eliminated by the simple insertion of computer graphics courses. Computer graphics have also generated a distancing (a barrier in communication) between teachers (who used pencil 
and paper as a tool during their training) and students (who have always used the computer as a tool). Another negative point in the use of computer graphics software is that they can inhibit to creativity as they tend to limit the student to the solutions provided by pre-established elements they contain.

Among the results presented with the use of this hybrid methodology (although not yet integrated-since it is in the test and adaptation phase, only used in certain disciplines by certain teachers), we can highlight a greater degree of interest and participation of students in the classroom and extra class work, an improvement in the accuracy and quality of the presentation of the work, an increase in productivity, and without doubt, a training of professionals better suited to the demands of the labor market without, however, harming the student's reasoning, thereby contributing to meaningful learning.

The results obtained with the use of this methodology have been significant, but there is still much to be done during each semester in the search for improvements of the methodological process. New alternatives have been tested in order to improve the teaching-learning process.

For example, all the changes performed in the Technical Drawing 3 discipline reflect suggestions given by students, generated by difficulties encountered during the semester. As recommendations for the following semesters, it is planned to introduce a graphic animation that allows students to visualize the objects developed in the computer, either a house or a high rise building, both internally and externally, as well as to help them in the representation and the generation of the floor plans, cross sections and facades from the sectioning of the model. It is also intending to include the use of BIM software.

For the following semesters we hope to count on the collaboration and integration of the professors of the disciplines of Three-dimensional Graphic Geometry and Descriptive Geometry so that, through an integrated project between the contents of these disciplines, we can improve the learning of our students and reduce the problems presented in the diagnosis.

\section{References}

[1] Silva, W. R. e, and LIRA, A. N. da C. 2001. "Uma Nova Metodologia Utilizando Multimídia-Computação Gráfica Aplicada e Geometria Descritiva.” In Proceedings of the : Anais do GRAPHICA 2001-III Congresso Internacional de Engenharia Gráfica nas Artes e no Desenho/14 ${ }^{\circ}$ Simpósio Nacional de Geometria Descritiva e Desenho Técnico. Anais. Ouro Preto: UFOP/ETFOP.

[2] Vianello, G. C. A. 2001. "Construindo o Conhecimento a Partir de Situações Reais.” In Proceedings of the Anais do GRAPHICA 2001-III Congresso Internacional de Engenharia Gráfica nas Artes e no Desenho $/ 14^{\circ}$ Simpósio Nacional de Geometria Descritiva e Desenho Técnico. Anais. Ouro Preto: UFOP/ETFOP.

[3] Maia, L. 2000. “A Teoria dos Campos Conceituais.” Um novo Olhar para a Formação, In: Revista do GEPEM. Rio de Janeiro.

[4] Carvalho, G. L. 2004. “Ambientes Cognitivos para Projetação: Um Estudo Relacional entre as Mídias Tradicional e Digital na Concepção do Projeto Arquitetônico.” 260p. Tese (doutorado)-Universidade Federal de Pernambuco. CAC. Desenvolvimento Urbano.

[5] Cabral Filho, J. 1996. "Formal Games and Interactive Design: Computers as Formal Devices for Informal Interaction between Clients and Architects.” Ph.D. thesis, Sheffield University.

[6] Goulette, J-P. 1997. "Représentations des Connaissances Spatiales pour la Conception Architecturale. Contribution au Raisonnment Spatiales pour la Conceptio Architecturale.” Contribution au Raisonnement Spatial Qualitatif, Thèse (Doctorat)-Université Paul Sabatier-Toulouse III, Toulouse, France. 